E. Moreno Guillamont • C. M. Lino • M. L. Baeta •

A. S. Pena $\cdot$ M. I. N. Silveira $\cdot$ J. Mañes Vinuesa

\title{
A comparative study of extraction apparatus in HPLC analysis of ochratoxin A in muscle
}

Received: 13 June 2005 / Revised: 22 July 2005 / Accepted: 28 July 2005 / Published online: 13 September 2005

C) Springer-Verlag 2005

\begin{abstract}
Ochratoxin A (OTA) is a secondary fungal metabolite produced by several moulds, mainly by Aspergillus ochraceus and by Penicillium verrucosum, that occurs in meat products. The aim of this work was to optimize an efficient extraction procedure for the determination of OTA in muscle tissue in order to assess its occurrence in meat samples. Three different apparatus, a Waring blender, a switching apparatus, and an ultrasonic processor, were evaluated to verify the efficiency of extraction. The analytical methods proposed involve the extraction with chloroformorthophosphoric acid, cleanup through an immunoaffinity column, high-performance liquid chromatography/fluorescence detection for separation and identification of OTA, and confirmation with liquid chromatography/FD after methylation of OTA in muscle tissue. The limit of quantification of the proposed method was $0.04 \mu \mathrm{g} \mathrm{kg}^{-1}$. Recoveries of OTA, using switching apparatus, ranged from 90.3 to $103.2 \%$ for chicken muscle spiked at 2.4 and $0.48 \mu \mathrm{g} \mathrm{kg}^{-1}$, respectively, with a within-day relative standard deviation of 17 and $15.3 \%$. The proposed method was applied to 38 chicken, swine, and turkey muscle samples and the presence of OTA was confirmed in five samples. Finally, the estimated daily intake of OTA in this study was between $23 \mathrm{pg} \mathrm{kg}^{-1}$ body weight per day for swine samples and $18 \mathrm{pg} \mathrm{kg}^{-1}$ body weight per day for turkey samples.
\end{abstract}

E. Moreno Guillamont · J. Mañes Vinuesa Laboratory of Food Chemistry and Toxicology,

Faculty of Pharmacy,

University of Valencia,

46100 Burjassot,

Valencia, Spain

C. M. Lino $(\bowtie) \cdot$ M. L. Baeta · A. S. Pena · M. I. N. Silveira

Group of Bromatology, CEF,

Faculty of Pharmacy,

University of Coimbra,

3000 Coimbra, Portugal

e-mail: cmlino@ci.uc.pt

Tel.: +351-239-859994

Fax: $+351-239-87126$
Keywords Ochratoxin A - Muscle - Waring blender . Switching apparatus · Ultrasonic processor

\section{Introduction}

Ochratoxin A (OTA) is a secondary fungal metabolite produced by several moulds, mainly by Aspergillus alutaceus var. alutaceus Barkely \& Curtis (formerly A. ochraceus $\mathrm{K}$. Wilh.), in warmer and tropical parts of the world, and Penicillium verrucosum, in temperate climates $[1,2]$. Penicillium verrucosum is especially associated with stored cereals, although it has also been isolated from meat and fish [2-8]. Aspergillus ochraceus is common on coffee, spices, and processed meat [9].

It is a nephrotoxic mycotoxin widely detected as a contaminant of agricultural commodities such as cereals [10], that it is further transmitted to animals and humans. The occurrence of OTA in meat products is due to transmission into muscle, kidney, liver, and blood in animals fed with natural contaminated feed [11].

Contaminated foods had been recognized as a possible threat to human health [12]. The toxicological profile includes nephrotoxicity, causing both acute and chronic lesions of kidneys [13], and OTA has been suspected of being involved in the aetiology of Balkan endemic nephropathy [14], a disease characterized by progressive renal fibrosis in humans mainly occurring in some areas of southeastern Europe, and its involvement has been implied in urinary tract tumours. OTA is classified as a possible carcinogen for humans (group 2B) by the International Agency for Research on Cancer [15].

Exposure to OTA is worldwide, as is known by it having been detected in human serum in many countries [16]; therefore, evaluation of OTA levels in different food items is necessary to provide data about exposure and to evaluate the possible human health risk of OTA.

A few analytical methods for determining OTA in muscle have been reported. These methods generally involve liquid extraction with solvents, such as mixtures of ethyl acetate-phosphoric acid [6,7], acidic chloroform [8], 
or dichloromethane-ethanol-phosphoric acid [5]. For cleanup, some procedures have been tried for different extracts, but the use of immunoaffinity columns (IAC) has been well documented for muscle [6-8] owing to its specificity. Solid-phase extraction with $\mathrm{C}_{18}$ adsorbent [6] and liquid partition with dichloromethane [5] or sodium hydrogencarbonate has been also used [6]. Detection and quantification is usually made by liquid chromatography with fluorescence detection $[5-8,14,17,18]$. However, immunochemical methods such as enzyme-linked immunochemical methods and chromatographic methods such as thin-layer chromatography, gas chromatography with mass spectrometry detection, and liquid chromatography with mass spectrometry or tandem mass spectrometry detection have also been used $[14,18]$.

The aim of our research was to verify the efficiency of extraction using three different apparatus, a Waring blender, a switching apparatus, and an ultrasonic processor, in the determination of OTA in muscle tissue, in order to assess its occurrence in meat samples. An extraction procedure with a chloroform-orthophosphoric acid mixture and partition with sodium hydrogencarbonate solution was used, and positive samples were confirmed by methylation of OTA.

After the validation procedure, the switching apparatus was applied to real samples of chicken, swine, and turkey muscle collected in the central zone of Portugal in order to evaluate OTA levels. The method was useful for the assessment of the estimated daily intake of OTA.

\section{Experimental}

\section{Apparatus}

A 400-W Fagor BV 401C Waring blender (PRC, Portugal), $230 \mathrm{~V}$ and $50 \mathrm{~Hz}$, and a 165-W Ufesa MBP-703 switching apparatus, $230 \mathrm{~V}, 50 \mathrm{~Hz}$, were used. Also a 375-W Vibra Cell 375 ultrasonic processor from Vibra Cell-Sonics \& Materials (Danbury, CT, USA) with a standard probe of titanium alloy, Ti $6 \mathrm{~V} \mathrm{Al} 4 \mathrm{~V}(7 \mathrm{~mm} \times 140 \mathrm{~mm}), 220 \mathrm{~V}$, $20 \mathrm{~Hz}$, was used with the following conditions: timer $300 \mathrm{~s}$; cycle 70; output control 5, and pulser $6 \mathrm{~s}$.

A high-performance liquid chromatography (HPLC) system consisting of a pump, model 307 (Gilson, France), one 20- $\mu$ l injection Rheodyne, model 7125 (Rheodyne, Cotati, CA, USA), a guard column, $\mathrm{C}_{18}-5 \mu \mathrm{m}$ Nucleosil $120 \mathrm{KS}(30-\mathrm{mm} \times 4-\mathrm{mm}$ inner diameter, i.d.), and a column, $\mathrm{C}_{18}-5 \mu \mathrm{m}$ Nucleosil $100(250-\mathrm{mm} \times 4.6-\mathrm{mm}$ i.d. $)$ were used. A spectrofluorimeter, model LS-3B (PerkinElmer, USA), was connected to the HPLC system. The detections were made using $333 \mathrm{~nm}$ for excitation and $460 \mathrm{~nm}$ for emission. An integrator, model 3390A (Hewlett-Packard, USA), was used to measure peak areas. The mobile phase consisted of water-acetonitrile-glacial acetic acid (49.5: 49.5:1.0) at a flow rate of $1 \mathrm{ml} \mathrm{min}{ }^{-1}$. The isocratic analysis under the conditions described allows the elution of
OTA with good resolution, with a retention time of $11.71 \mathrm{~min}$.

\section{Chemicals}

HPLC grade acetonitrile, toluene, methanol, and chloroform ISO were purchased from Carlo Erba (Milan, Italy). Analytical grade glacial acetic acid, $85 \%$ orthophosphoric acid, hydrochloric acid, and sodium hydrogencarbonate were obtained from Merck (Darmstadt, Germany). Deionized water was prepared from a Milli Q system (Millipore, Bedford, MA, USA). Boron trifluoride-methanol (14\% solution) was obtained from Sigma Chemicals Co. (St. Louis, USA). OTA was obtained from Sigma Chemicals Co.

Ochratest IAC were from VICAM (Watertown, USA).

The mobile phase consisted of acetonitrile-water-glacial acetic acid (49.5:49.5:1.0).

A standard solution of OTA was prepared from the OTA vial purchased from Sigma Chemicals Co. The concentration and purity of standard solutions were evaluated by AOAC official methods [19]. The stock solution was made in $4 \mathrm{ml}$ toluene-acetic acid (99:1) at $250 \mu \mathrm{g} \mathrm{ml}{ }^{-1}$. An intermediate solution was prepared at $10 \mu \mathrm{g} \mathrm{ml}^{-1}$, diluting $1 \mathrm{ml}$ of stock solution with $25 \mathrm{ml}$ toluene-acetic acid (99:1). For fortification essays, a working solution was prepared in toluene-acetic acid (99:1) at 1,000 $\mathrm{ng} \mathrm{ml}^{-1}$.

For the calibration curve, one working solution for calibration was prepared by evaporating $10 \mu \mathrm{l}$ of stock solution to dryness, and diluting it to $10 \mathrm{ml}$ with a mobile phase $\left(250 \mathrm{ng} \mathrm{ml}^{-1}\right)$. The others were prepared by diluting this solution to the following concentrations: $25.0,20.0$, $15.0,10.0,5.0$, and $2.5 \mathrm{ng} \mathrm{ml}^{-1}$. All solutions were stored in amber flasks to protect them from light.

\section{Sampling}

Thirty-eight muscle samples purchased in different supermarkets located in Coimbra city, 13 of turkey and swine meat and 12 of chicken meat, were collected from October 2002 to February 2003. The samples were covered in aluminium foil, frozen, and stored at $-20^{\circ} \mathrm{C}$.

\section{Recoveries}

For recovery studies, using a Waring blender and switching apparatus, $4.8 \mu \mathrm{l}$ of the OTA working solution prepared in toluene-acetic acid (99:1) at 1,000 $\mathrm{ng} \mathrm{ml}^{-1}$ was added to $10 \mathrm{~g}$ of chicken muscle and allowed to stand for $15 \mathrm{~min}$ at room temperature before extraction, for three replications. The same was done for fortification at 1.0 and at $2.4 \mu \mathrm{g}$ $\mathrm{kg}^{-1}$, by adding 10 and $24 \mu \mathrm{l}$, respectively, of the same working solution. Using the ultrasonic processor, only a fortification level of $2.4 \mu \mathrm{g} \mathrm{kg}^{-1}$ was tried (Table 1). 
Table 1 Accuracy and precision of three methods used for ochratoxin A (OTA) extraction in muscle

\begin{tabular}{lcll}
\hline $\begin{array}{l}\text { Fortification level } \\
\left(\mu \mathrm{kg}^{-1}\right)\end{array}$ & \multicolumn{2}{l}{$R \pm \mathrm{RSD}^{\mathrm{a}}$} & \\
\cline { 2 - 4 } & $\begin{array}{l}\text { Waring } \\
\text { blender }\end{array}$ & $\begin{array}{l}\text { Switching } \\
\text { apparatus }\end{array}$ & $\begin{array}{l}\text { Ultrasonic } \\
\text { processor }\end{array}$ \\
\hline 0.48 & $85.9 \pm 1.5$ & $103.2 \pm 20.4$ & - \\
1.00 & $67.6 \pm 9.3$ & $95.3 \pm 15.3$ & - \\
2.40 & $104.5 \pm 11.4$ & $90.3 \pm 17.0$ & $44.1 \pm 11.8$ \\
\hline
\end{tabular}

${ }^{\mathrm{a}} n=3$

\section{Extraction and cleanup procedures}

Method with the Waring blender

Chicken muscle $(10 \mathrm{~g})$ was homogenized with a chloroform-orthophosphoric acid $85 \%$ mixture $(100 \mathrm{ml}+4 \mathrm{ml})$ for $2 \mathrm{~min}$. The mixture was filtered through a Whatman $113 \mathrm{~V}$ filter paper, and then in a separating funnel, $50 \mathrm{ml}$ chloroformic extract was partitioned with $100 \mathrm{ml}$ of $1 \mathrm{M}$ sodium hydrogencarbonate solution. An aliquot of the aqueous phase $(45 \mathrm{ml})$ was added to $15 \mathrm{ml}$ water. A $50-\mathrm{ml}$ aliquot of this solution was passed through the IAC for cleanup. After the solution had passed through the column, the column was washed with water and dried by air. The OTA was eluted with $2 \mathrm{ml}$ methanol with a vacuum manifold. The methanol was dried at $\pm 40^{\circ} \mathrm{C}$, under one gentle nitrogen stream, and the residue was redissolved in $250 \mu 1$ of the mobile phase and injected in the HPLC system.

Method with the switching apparatus

The sample was transferred to a tumbler, the extraction mixture was added, and the switching apparatus was applied for $2 \mathrm{~min}$. The following steps were in accordance with the previously described method.

\section{Method with the ultrasonic processor}

The sample was transferred to a centrifuge Pyrex test tube, the extraction mixture was added and the resulting mixture was sonicated with a probe under the previously described conditions, with the tube immersed in an ice and salt bath. The following steps were similar to the those of the previously described method.

\section{Chemical confirmation procedures}

The first confirmation was performed according to the method of Zimmerli and Dick [1]: $200 \mu$ lof the extract was diluted to $2.5 \mathrm{ml}$ with methanol and $0.1 \mathrm{ml}$ of $37 \%$ concentrated $\mathrm{HCl}$ was added. After standing overnight at room temperature, the methanol was evaporated and the residue was dissolved in $250 \mu \mathrm{l}$ of the mobile phase.

Another confirmation was carried out following the procedure of Castegnaro et al. [20]. Sample extracts were evaporated to dryness, $150 \mu \mathrm{BF}_{3}(14 \%$ methanolic solution) was added, and the mixture was left at $60^{\circ} \mathrm{C}$ for $10 \mathrm{~min}$. After evaporation, the residue was dissolved in $150 \mu \mathrm{l}$ water-acetonitrile-glacial acetic acid (49.5:49.5:1.0). The OTA methyl esters were analysed according to the HPLC method described earlier.

\section{Statistical analysis}

Database management and statistical analysis were performed with SPSS 10.0 Microsoft Windows version. The differences in the OTA levels between three different muscles were tested with the $\chi^{2}$ test. $P \leq 0.05$ (two-tailed) was considered to be statistically significant. For statistical analysis, if the concentration was below the limit of quantification (LOQ) it was set to $50 \%$ of that limit when the mean and standard deviation were calculated.

\section{Results and discussion}

The calibration curves were obtained using the linear leastsquares regression procedure of the peak area versus the concentration. The linearity for OTA, in the working standard solutions at three determinations of five concentration levels, between 2.5 and $25 \mathrm{ng} \mathrm{ml}^{-1}$ was good as shown by the fact that the correlation coefficients $\left(r^{2}\right)$ are above 0.9914 .

To verify the absence of potential interfering compounds around the retention time of OTA, a number of representative blank meat samples from different origins $(n=6)$ were analysed in order to assess the specificity of the method. No interferences were observed in the region of interest where the OTA was eluted (Fig. 1). Figure 1 shows the HPLCspectrofluorimeter chromatograms of the OTA standard, one chicken blank sample, and one chicken muscle sample fortified using the switching apparatus.

The chloroform, previously applied by Curtui et al. [8], used as an extraction solvent was successfully used to extract OTA from muscle. The accuracy was determined by calculating the mean recovery values for each fortification level (Table 1). The recovery values, using the Waring blender for extraction, were $85.9,67.6$, and $104.5 \%$ for fortification levels of $0.48,1.0$, and $2.4 \mu \mathrm{g} \mathrm{kg}^{-1}$, respectively. With the switching apparatus, those levels were 103.2, 95.3, and 90.3\%, respectively. Using an ultrasonic processor, the results were not adequate, $44.1 \pm 11.8 \%$ (Table 1). The worst results obtained with the ultrasonic method, when the extraction solvent used was the same, could be explained by an improvement of the mechanical procedure of the other two methods, which leads to better 


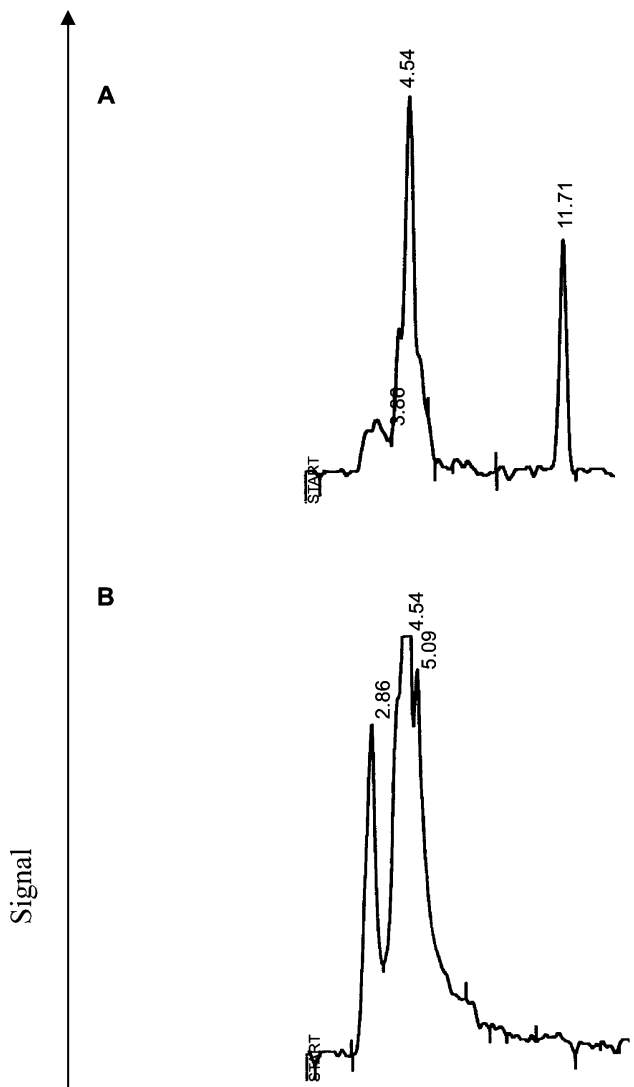

C

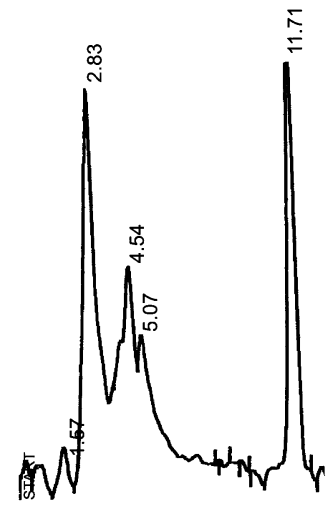

Retention time (minutes)

Fig. 1 Liquid chromatography-spectrofluorimetric chromatogram of ochratoxin A (OTA) standard (a) (retention time $11.71 \mathrm{~min}$ ), one chicken blank sample (b), and one chicken muscle sample fortified at $2.4 \mu \mathrm{gkg}-1$ (c), using the switching apparatus

OTA extraction efficiency from the tissues, once OTA is bound to the albumin fraction. This explanation is in accordance with the good results obtained for the blender and switching methods, based on the same mechanical basis.

These methods, for the levels studied, indicated an adequate methodology for quantification of OTA in muscle samples, when compared with other methodologies. The results obtained are excellent when compared with those obtained using similar or different extraction techniques, such as with the Waring blender, 53\% [7], and the Ultra Turrax, 74\% [6].

However, the bakelite material from the Waring blender is attacked by chloroform, with the respective deterioration during the successive analysis. Therefore, the switching method was the applied method.

The precision was calculated by intraday repeatability $(n=3)$ and interday repeatability ( 3 days). The repeatability obtained oscillated between $11.4 \%$ at $2.4 \mu \mathrm{g} \mathrm{kg}^{-1}$ and $1.5 \%$ at $0.48 \mu \mathrm{g} \mathrm{kg}^{-1}$ for the Waring blender, and between $15.3 \%$ at $1.0 \mu \mathrm{g} \mathrm{kg}^{-1}$ and $20.4 \%$ at $0.48 \mu \mathrm{g} \mathrm{kg}^{-1}$ when the switching apparatus was used. The repeatability values from different methods oscillated between 8 [6] and 13.9\% [8].

The 3-day repeatability obtained with the switching apparatus was calculated on the basis of analysis at 1.0 and $2.4 \mu \mathrm{g} \mathrm{kg}^{-1}$ per day for 3 days with relative standard deviations (RSD) of 11.6 and $12.3 \%$ respectively (Table 2).

For both the Waring blender and the switching apparatus, the limit of detection (LOD), based on a signal-to-noise ratio of $3: 1$, was $0.01 \mu \mathrm{g} \mathrm{kg}^{-1}$. The LOQ was determined by the signal-to-noise approach, defined as that level resulting in a signal-to-noise ratio of approximately 10:1. The LOQ of the method was $0.04 \mu \mathrm{g} \mathrm{kg}^{-1}$. From an investigation of the LOD values from the different methods used for OTA determination in muscle, the results obtained with the switching apparatus are of the same order as those reported by Jorgensen [5], are better than those reported by Jorgensen and Petersen [7], using the Waring blender, and by Monaci et al. [6], but are lower than the results obtained by Curtui et al. [8]. Some researchers did not report LOQ values $[5,8]$, and others found lower LOQ values $[6,7]$.

For confirmation, the OTA was converted into OTA methyl ester and two different procedures were evaluated. Positive confirmation was based on the disappearance of the OTA peak and the appearance of a new one, corresponding to OTA methyl ester, at a retention time of $21.3 \mathrm{~min}$. The recovery rate of the methyl ester was higher, $93 \%$, for boron trifluoride-methanol solution when compared with the rate using the method of Zimmerli and Dick [1], 79\%, with good blanks, in spite of the appearance of one peak with a different retention time, which did not

Table 2 Results of repeatability and 3-day repeatability of OTA from muscle by method with switching apparatus

Level $\left(\mu \mathrm{g} \mathrm{kg}^{-1}\right)$ Repeatability $\mathrm{RSD}^{\mathrm{a}}{ }^{\mathrm{a}}$ 3-day repeatability $\mathrm{RSD} \%{ }^{\mathrm{b}}$

$\begin{array}{lll}1.00 & 15.3 & 11.6 \\ 2.40 & 17.0 & 12.3\end{array}$

$\begin{array}{lll}2.40 & 17.0 & 12.3\end{array}$

${ }^{\text {a }}$ Repeatability on the basis of three replicates at 1.0 and $2.4 \mu \mathrm{g} \mathrm{kg}^{-1}$ within the same day

${ }^{\mathrm{b}}$ Three-day repeatability on the basis of analysis at 1.0 and $2.4 \mu \mathrm{g}$ $\mathrm{kg}^{-1}$ per day 
Table 3 Incidence of OTA in muscle samples analysed by the proposed method

${ }^{a}$ Range

\begin{tabular}{llllll}
\hline Muscle sample & No. of samples & \multicolumn{2}{l}{ No. of samples with OTA level } & Value of OTA \\
\cline { 3 - 4 } & & LOD-LOQ & $>$ LOQ & $\begin{array}{l}\text { Mean } \pm \text { SD } \\
\left(\mu \mathrm{kg}^{-1}\right)\end{array}$ & $\left(\mu \mathrm{kg}^{-1}\right)$ \\
\hline Swine & 13 & 6 & 1 & 0.12 & $0.01 \pm 0.03$ \\
Turkey & 13 & 5 & 4 & $0.04-0.01^{\mathrm{a}}$ & $0.02 \pm 0.03$ \\
Chicken & 12 & 9 & 0 & - & - \\
\hline
\end{tabular}

interfere. For these reasons, the confirmation of OTA in positive samples was performed according to the first method.

\section{Application to real samples}

The method using the switching apparatus for the extraction was successfully applied to 38 muscle samples, 12 of chicken, 13 of swine, and 13 of turkey (Table 3 ).

OTA was found in one swine muscle that contained $0.12 \mu \mathrm{g} \mathrm{kg}^{-1}$ (mean $0.01 \pm 0.03 \mu \mathrm{g} \mathrm{kg}^{-1}$ ), and in four turkey muscle samples with levels ranging from 0.04 to $0.01 \mu \mathrm{g}$ $\mathrm{kg}^{-1}$ (mean $0.02 \pm 0.03 \mu \mathrm{g} \mathrm{kg}^{-1}$ ), while no OTA was found in any chicken sample. Figure 2 represents HPLC-spectrofluometric chromatograms of one positive sample and OTA methyl ester after boron fluoride-methanol derivatization.

The results of the statistical analysis to determine the differences in the mean concentrations of OTA between the three analysed populations revealed that they are not significant, the $P$ values being $0.975,0.753$, and 0.969 .

Surveys carried out in Denmark in 1993 and 1994 to estimate OTA levels in pork and poultry revealed low levels. The mean contents of conventional pork, turkey, and chicken samples were $0.11,0.02$, and $0.03 \mu \mathrm{g} \mathrm{kg}{ }^{-1}$, respectively. The highest values of conventional pork, tur$\mathrm{key}$, and chicken samples were $1.3,0.11$, and $0.18 \mu \mathrm{g} \mathrm{kg}^{-1}$, respectively [5]. In 1999, another Danish survey showed OTA contents in swine meat samples ranging from below the LOD to $2.9 \mu \mathrm{g} \mathrm{kg}^{-1}$ (mean $0.12 \mu \mathrm{g} \mathrm{kg}^{-1}$ ) [7]. A similar study conducted in Romania, in 1998, demonstrated higher values, $0.53 \mu \mathrm{g} \mathrm{kg}^{-1}$, but the mean level found in swine muscle was similar, $0.15 \mu \mathrm{g} \mathrm{kg}^{-1}$ [8].

In our study the incidence of OTA in swine muscle, $7.7 \%$, was low compared with that for swine muscle from other countries, for example $17 \%$ in Romania [8], but in turkey samples it was $30.8 \%$. In Italy, 12 pig muscle tissues were analysed and OTA was not detected [6].

As far as regulations are concerned, only some countries set specific regulations for OTA in several commodities. The current limits range from 1 to $5 \mu \mathrm{g} \mathrm{kg}^{-1}$ for children and infant foods, from 2 to $50 \mu \mathrm{g} \mathrm{kg}^{-1}$ for foods, and from 5 to $300 \mu \mathrm{g} \mathrm{kg}^{-1}$ for animal feeds. Within the EU the suggested tolerance levels are $1 \mu \mathrm{g} \mathrm{kg}^{-1}$ for infant foods and at $5 \mu \mathrm{g} \mathrm{kg}^{-1}$ for cereals [21]. In 2005, the European Commission established maximum levels between $0.5 \mu \mathrm{g}$ $\mathrm{kg}^{-1}$ for baby foods and processed cereal-based foods for infants and young children and for dietary foods for special medical purposes intended specifically for infants and $10 \mu \mathrm{g} \mathrm{kg}^{-1}$ for dried vine fruit, soluble coffee, and wine [22]. In Romania, the maximum allowed limit for meat is
$5 \mu \mathrm{gg}^{-1}$ [8]. Denmark has enforced limits between 10 and $25 \mathrm{\mu g} \mathrm{kg}^{-1}$ in pig kidney, for condemnation of liver and kidney, and a condemnation level for the entire carcase of $25 \mu \mathrm{g} \mathrm{kg}^{-1}$ in pig kidney [7]. In Italy, since 1999, a guideline value of $1 \mathrm{\mu g} \mathrm{kg}^{-1}$ in pork meat and derived products has been recommended [6]. None of samples analysed from the central zone of Portugal exceeded those values, showing that OTA incidence is far from representing a real concern for consumers.

For swine muscle collected in the central zone of Portugal, the average sample contamination of OTA was $0.01 \mu \mathrm{g} \mathrm{kg}^{-1}$, according to our data. Assuming that the estimation of the average daily intake of swine in the Portuguese population is $149 \mathrm{~g}$ per person per day [23] and

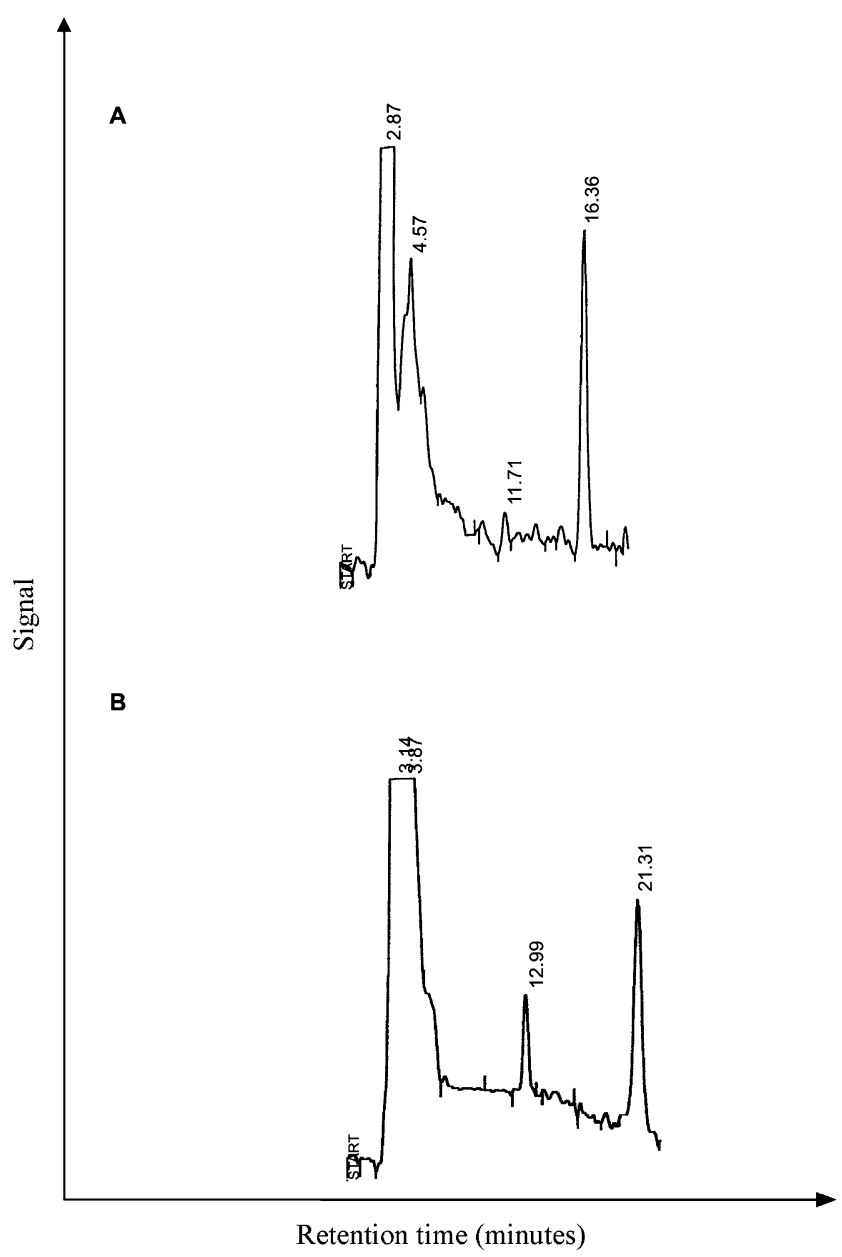

Fig. 2 High-performance liquid chromatography-spectrofluometric chromatograms of one positive sample (a) (retention time $11.71 \mathrm{~min}$ ) and OTA methyl ester after boron fluoride-methanol derivatization (b) 
that an adult body weighs $60 \mathrm{~kg}$, the estimated daily intake (EDI) of OTA in this study was $0.023 \mathrm{ng} \mathrm{kg}^{-1}$ body weight per day. This value represents 0.45 and $0.14 \%$ of the provisional tolerable daily intake (PTDI) according to the Scientific Committee on Food of the European Commission, $5 \mathrm{ng} \mathrm{kg}^{-1}$ body weight per day [24] and the WHO Committee of Experts on Food Additives, $16 \mathrm{ng} \mathrm{kg}^{-1}$ body weight per day [25], respectively, reaching maximum values of 6 and $1.9 \%$ for the positive sample.

For turkey muscle, the mean concentration was $0.02 \mu \mathrm{g}$ $\mathrm{kg}^{-1}$, and the consumption data was $53 \mathrm{~g}$ per person per day [22]. On the basis of these data, the EDI of OTA is $0.018 \mathrm{ng} \mathrm{kg}^{-1}$ body weight per day, and represents 0.35 and $0.11 \%$ of the PTDI. According to data from Portuguese Food Balance [26], meat consumption reached, in 2001, $102.9 \mathrm{~kg}$ per person per year, which means $281.91 \mathrm{~g}$ per person per day, fifth place in the EU rank. Accepting this, the EDI for turkey muscle would reach nearly $0.1 \mathrm{ng} \mathrm{kg}^{-1}$ body weight per day, which leads to increases of PTDI to 2 and $0.6 \%$ according to the estimated values.

\section{Conclusions}

The use of the switching apparatus for extraction revealed good efficiency of extraction, and combined with IAC cleanup and liquid chromatography-spectrofluorimetric detection showed good analytical performance for OTA determination in muscle, showing better results than other published results. This procedure has been shown to be reliable for muscle matrix at low level, $0.04 \mu \mathrm{g} \mathrm{kg}^{-1}$.

The application of the procedure to 38 muscle tissue samples from the central zone of Portugal has demonstrated that none of them contained levels above the European maximum levels for other item foods.

The estimated daily intake of OTA, in the three different muscle tissues, is below the tolerable daily intake, demonstrating that OTA incidence is far from representing a real concern for consumers.

Acknowledgements This work was carried out with financial support, which is gratefully acknowledged, from the FCT and FEDER/ POCTI. The authors are also gratefully recognized to Tiago L. Morais for statistical analysis.

\section{References}

1. Zimmerli B, Dick R (1995) J Chromatogr B 666:85-99

2. Moss MO (1996) Food Addit Contam 13:5-9

3. Marquardt RR, Frolich AA (1992) J Anim Sci 70:3968-3988

4. Valenta A (1998) J Chromatogr A 815:75-92

5. Jorgensen K (1998) Food Addit Contam 15:550-554

6. Monaci L, Tantillo G, Palmisano F (2004) Anal Biochem 378:1777-1782

7. Jorgensen K, Petersen A (2002) Food Addit Contam 19:562567

8. Curtui VG, Gareis M, Usleber E, Märtlbauer E (2001) Food Addit Contam 18:730-738

9. Kuiper-Goodman T, Scott PM (1989) Biomed Environ Sci 2:179-248

10. Scott PM (1996) Food Addit Contam 13:19-21

11. Gareis M (1996) Food Addit Contam 13:35-37

12. Jodlbauer J, Maier NM, Lindner W (2002) J Chromatogr A 945:45-63

13. Creppy EE (1999) J Toxicol Toxin Rev 18:277-293

14. Blesa J, Berrada H, Soriano JM, Moltó JC, Mañes J (2004) J Chromatogr A 1046:127-131

15. IARC (eds) (1993) Ochratoxin A. IARC monographs on the evaluation of carcinogenic risks to humans, vol 56. IARC, Lyon, pp 489-521

16. Grosso F, Saïd S, Mabrouk I, Fremy JM, Castegnaro M, Jemmali M, Dragacci S (2003) Food Chem Toxicol 41:11331140

17. Pena A, Cerejo F, Lino C, Silveira I (2005) Anal Biochem 382:1288-1293

18. Matrella R, Monaci L, Milillo MA, Palmisano F, Tantillo MG (2006) Food Control 17:114-117

19. AOAC (1995) Official method 970.44B. Official methods of analysis, vol II, 16th (edn.) AOAC International, Washington, DC

20. Castegnaro M, Maru V, Maru G, Ruiz-Lopez MD (1990) Analyst 115:129-131

21. Van Egmond HP (1996) Food Addit Contam 13:11-13

22. Commission Regulation (EC) no $123 / 2005$ of 26 January 2005 amending regulation (EC) no 466/2001 as regard ochratoxin A. Official Journal of the European Union, L 25/3-L 25/5, 28 January 2005

23. WHO-food safety issues, GEMS/food regional diets: regional per capita consumption of raw and semi-processed agricultural commodities, September 2003, p 22

24. Commission of the European Communities, Directorate General XXIV, Scientific Committee on Food. Outcome of discussion 14, expressed on 17 September 1998

25. WHO (1991) JECFA evaluation of certain food additives and contaminants, 37th report. WHO technical report series no 806, p 29

26. INE (2004) Hábitos alimentares dos portugueses 2004. Available at http://alea.ine.pt/html/actual/html/act41.html. Accessed 29 October 2004 